\title{
OPTIMASI DESAIN EVAPORATOR DAN KONDE NSER UNTUK SISTEM PENDINGIN KABIN KENDARAAN
}

\section{DESIGN OPTIMIZATION OF EVAPORATOR AND CONDENSER FOR COOLING SYSTEM OF PASSENGER VEHICLE CABIN}

\author{
I G A Uttariyani \\ Komplek PUSPIPTEK Gd. 230 BT2MP-BPPT, Serpong, Tangerang Selatan \\ e-mail:a.uttariyani@bppt.go.id
}

\begin{abstract}
Abstrak
Pada perancangan kondensor ataupun evaporator, efektifitas pertukaran panas merupakan bagian yang terpenting untuk meningkatkan kinerja dari peralatan penukar kalor. Pada kondensor jenis fin tube salah satu parameter perancangan yang paling penting untuk meningkatkan efektivitas pertukaran panas adalah urutan dan peletakkan tube-tube untuk mengalirkan refrigeran pada tube-tube kondensor. Circuit tube menentukan distribusi refrigeran melalui kondensor yang berdampak pada massa refrigeran, pertukaran panas, penurunan tekanan, dan temperatur pada setiap tube. Paper ini membahas mengenai pembuatan sirkuit refrigerant di dalam peralatan penukar panas, dan mensimulasikan temperature refrigerant, temperature udara maupun fraksi uap pada setiap tube untuk menghasilkan desain yang optimal dengan menggunakan perangkat lunak EVAP-COND. Berdasarkan hasil optimasi dari beberapa konfigurasi sirkuit tube refrigeran didapatkan desain evaporator dan kondensor yang paling optimal dengan kapasitas pelepasan panas $26 \mathrm{~kW}$.
\end{abstract}

Kata kunci: Evaporator, Kondensor, Optimasi Desain, Susunan Tube

\begin{abstract}
Heat Exchanger effectiveness in designing the condenser or evaporator is an important part to improve the performance of the heat exchanger equipment. One of the most important design parameter for improving the effectiveness of heat exchange in the fin tube condenser type is the order and arrangement tubes to drain the refrigerant in the condenser tubes. Circuit tube determines the distribution of refrigerant through the condenser which impact on the masses refrigerants, heat exchangers, pressure drop, and temperature on each tube. In the paper, EVAP-COND software was used for creating refrigerant circuit in the heat exchanger equipment, and simulating the refrigerant temperature, air temperature and vapor fraction in each tube to produce the optimal design. The result showed that the most optimal design of evaporator and condenser for capacity of $26 \mathrm{~kW}$ heat release were obtained with multiple circuit configurations tube evaporator and condenser refrigerant.
\end{abstract}

Key words : Evaporator, Condenser, Design Optimization, Circuit Tube

Diterima (recieved) : 15 Mei 2016, Direvisi (Revised) : 3 Oktober 2016, Disetujui (Accepted) : 27 November 2016

\section{PENDAHULUAN}

Tujuan utama sistem pengkondisian udara adalah mempertahankan keadaan udara di dalam ruang yang meliputi pengaturan temperatur, kelembaban relatif, kecepatan sirkulasi udara maupun kualitas udara. Menjaga kenyamanan di dalam suatu ruangan atau kabin kendaraan atau alat transportasi adalah sangat sulit karena banyaknya variabel yang sering kali berubah baik berupa perubahan jumlah penumpang, kondisi buka tutup pintu, kondisi laju kendaraan maupun perubahan kondisi luar kabin.

Perhitungan beban pada kabin kendaran angkut penumpang terbagi ke dalam dua lokasi yaitu kabin depan dan kabin belakang, dimana setiap beban pendingin pada masing-masing kabin diatasi oleh satu evaporator, sedangkan kondensor harus mengatasi beban 
pendinginan dari dua evaporator. Ketika melakukan perancangan pada sistem pendingin, parameter penting yang diperlukan adalah melakukan estimasi beban pendingin yang meliputi beban metabolik penumpang, beban kebutuhan udara segar. Untuk dapat melakukan estimasi beban pendingin, diperlukan survei secara mendalam

Ketika melakukan perancangan pada sistem pendingin prosedur penting dan menjadi paling utama adalah dengan melakukan kalkulasi radiasi dan beban konduksi dari dinding ${ }^{1]}$. Untuk mendapatkan estimasi beban pendingin, diperlukan survei secara mendalam agar dapat dilakukan analisis yang detil terhadap sumbersumber beban pendinginan, sehingga dari estimasi tersebut dapat ditentukan jenis peralatan dan energi yang dipergunakan.

Pada perancangan komponen sistem pendingin evaporator dan kondensor, efektifitas pertukaran panas merupakan bagian yang terpenting untuk meningkatkan kinerja dari peralatan penukar kalor. Pada studi ini, perangkat lunak "Evap-Kond" dipergunakan untuk membuat sirkuit refrigerant di dalam peralatan penukar panas dan mensimulasikan temperature refrigerant, temperature udara maupun fraksi uap pada setiap tube untuk menghasilkan desain yang optimal. Tujuan dari kegiatan ini untuk mendapatkan desain dari fintube evaporator dan kondensor yang paling optimal dari beberapa konfigurasi sirkuit refrigeran untuk kabin depan kendaraan angkut dengan daya termal $9 \mathrm{~kW}$. Kegiatan ini merupakan kelanjutan dari kajian Perhitungan Beban Termal Pada Sistem Pengkondisian Udara Kendaraan Militer Pengangkut Personel ${ }^{7]}$

Paper ini berisikan hasil kajian terkait desain dari fin-tube evaporator dan kondensor yang paling optimal dari beberapa konfigurasi sirkuit refrigeran untuk kabin depan kendaraan angkut dengan daya termal $9 \mathrm{~kW}$.

\section{TINJ AUAN PUSTAKA}

Evaporator dan kondensor merupakan komponen utama dalam sistem pengkondisian udara kendaraan angkut. Evaporator berfungsi sebagai alat penyerap kalor dari lingkungan ke refrigerant, sehingga refrigerant akan mengalami perubahan fasa dari cair menjadi uap. Dalam proses pendinginan, pada umumnya temperatur permukaan bidang evaporator lebih rendah daripada titik embun dari udara masuk. Apabila udara ruangan menyentuh permukaan koil pendingin, uap air dalam udara akan mengembun sehingga koil menjadi basah"]

Sedangkan kondensor mempunyai fungsi sebagai komponen tempat terjadinya perpindahan panas dari fluida refrigeran ke udara luar. Pada sistem pengkondisian udara pada umumnya menggunakan tipe fin-tube untuk kondensor. Refrigeran mengalir sepanjang tube-tube, sedangkan udara dilewatkan melalui sirip-sirip di luar tube. Refrigeran keluar dari kompresor, masuk kondensor dalam kondisi panas lanjut (superheated), dan keluar dari kondensor dalam kondisi fluida subdingin (subcooled). Di dalam kondensor proses perpindahan panas terbagi dalam tiga kondisi yaitu panas lanjut (super heated), kondisi uap basah (saturated) dan sub dingin (subcooled) (2-3] $^{\text {. }}$.

Pada perancangan evaporator maupun kondensor, efektifitas pertukaran panas merupakan bagian yang terpenting untuk meningkatkan kinerja dari peralatan penukar kalor. Pada kondensor jenis fin tube salah satu parameter perancangan yang paling penting untuk meningkatkan efektivitas pertukaran panas adalah urutan dan peletakkan tube-tube untuk mengalirkan refrigeran pada tube-tube kondensor . Circuit tube menentukan distribusi refrigeran melalui kondensor yang berdampak pada massa refrigeran, pertukaran panas, penurunan tekanan, dan temperatur pada setiap tube. Circuit refrigerant pada umumnya ditentukan oleh matrik dan geometri yang meliputi diameter tube, pengaturan jarak tube dan fin, dan luas permukaan perpindahan panas $^{4,5,8]}$.

Salah satu perangkat lunak untuk merancang peralatan penukar kalor fin tube yang dapat mensimulasikan konfigurasi dari sirkuit tube adalah perangkat lunak "Evap Kond NIST". Gambar 1.menunjukkan matrik dari peralatan penukar panas fin tube yang di gunakan oleh perangkat lunak "Evap Kond". Konfigurasi dari tube digambarkan pada sisi samping koil peralatan penukar kalor, pada garis lurus memperlihatkan hubungan antar tube oleh $U$ tube sedangkan pada garis putus-putus hubungan terjadi pada sisi sebaliknya.Pada simulasi ini untuk masing-masing tube diberikan penomoran.

Perangkat lunak ini memudahkan pengguna untuk membuat sirkuit refrigerant di dalam peralatan penukar panas, dan dapat di gunakan untuk menghasilkan simulasi temperatur refrigerant, temperatur udara maupun fraksi uap pada setiap tube. Hasil-hasil ini dapat digunakan sebagai acuan pemakai untuk desain yang optimal. 


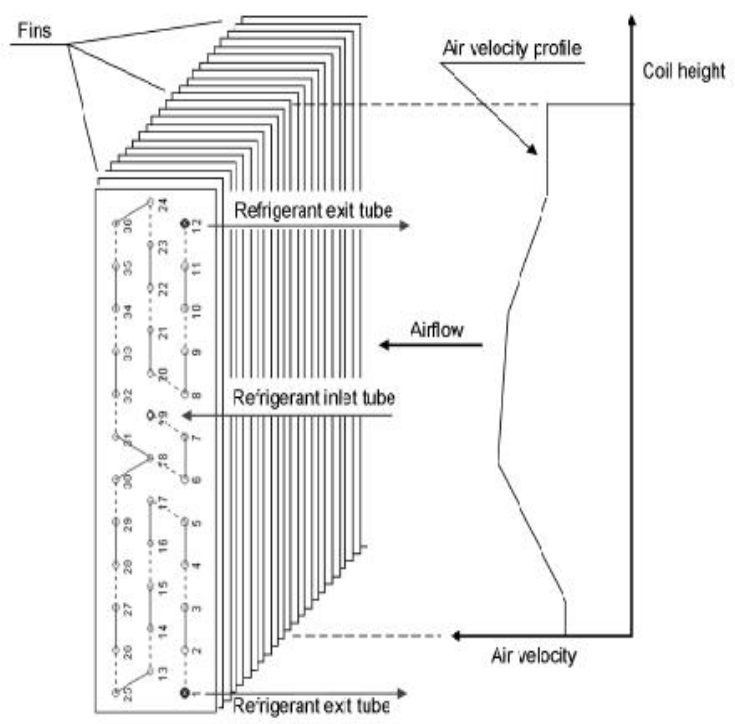

Gambar 1.

Konfigurasi dari peralatan penukar kalor dengan perangkat lunak "EVAP-KOND"

\section{METODE PENELITIAN}

\section{Perhitungan evaporator}

Perhitungan termal evaporator dilakukan dengan menggunakan perangkat lunak yang dibuat khusus untuk simulasi evaporator pada sistem pengkondisian udara. Langkah-langkah yang digunakan didalam desain evaporator meliputi:

1. Penetapan parameter operasi

Parameter yang digunakan sebagai data inputan dalam perancangan ini meliputi:

- Kondisi udara dengan $\mathrm{T}_{\text {inlet }}=26,5^{\circ} \mathrm{C}$ (evaporator)

- Kondisi udara luar

$\mathrm{T}_{\text {inlet }}=35^{\circ} \mathrm{C}, \mathrm{T}_{\text {outlet }}=40^{\circ} \mathrm{C}$

- Refrigeran yang digunakan : R-134a

Temperatur saturasi $=5^{\circ} \mathrm{C}$,

Tekanan kondensasi $=1492 \mathrm{kPa}$

Temperatur inlet kondensor $=104^{\circ} \mathrm{C}$

- Daya fan : 100 W.

2. Penentuan geometri evaporator Matriks geometri evaporator yang digunakan adalah sebagai berikut:

- Finned-tube panjang $=500 \mathrm{~mm}$

$\mathrm{OD}=10,21 \mathrm{~mm}, \mathrm{ID}=9,49 \mathrm{~mm}$, tube-pitch $=25,4 \mathrm{~mm}$ depth-row-pitch $=22 \mathrm{~mm}$.

- Jumlah row $=5$ dengan jumlah tube tiap row $=18$ berdasarkan data geometri evaporator terpasang.

- Bahan tube : tembaga/copper dan bahan fin : aluminium-flat (tebal $=0,33$ $\mathrm{mm}$, pitch $=3.175 \mathrm{~mm}$ )
Selain data batasan seperti telah ditunjukkan di paragraf sebelumnya, diperlukan lagi beberapa asumsi agar perhitungan termal dapat dilakukan. Asumsi-asumsi yang diambil mencakup:

- Tekanan udara inlet : $103 \mathrm{kPa}$.

- Kelembaban udara di inlet : $75 \% \mathrm{RH}$.

3. Penyusunan Konfigurasi Evaporator

Berdasarkan data-data di atas, disusunlah konfigurasi evaporator agar memiliki dimensi yang sesuai proporsional. Menurut Ding, Dkk, jumlah baris dan koneksi tube, maka dicari konfigurasi yang dapat memenuhi kondisi operasi yang telah ditentukan ${ }^{6}$. Pada Gambar 2 menunjukkan matrik geometri dan parameter-parameter yang digunakan di dalam merancang evaporator.

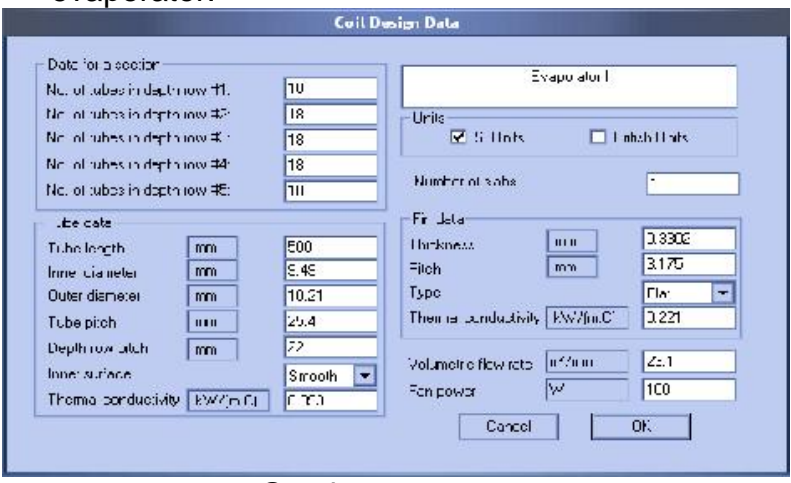

Gambar 2.

Data masukkan untuk perancangan evaporator

\section{Perhitungan kondensor}

Metode yang digunakan untuk mengoptimasi desain kondensor dengan membandingkan hasil simulasi dari beberapa hasil desain kondensor dengan berbagai konfigurasi circuit tube refrigeran.

Langkah-langkah yang digunakan didalam mengoptimasi desain kondensor meliputi:

1. Penetapan parameter operasi Parameter yang digunakan sebagai data inputan dalam perancangan ini nantinya digunakan untuk semua konfigurasi desain yang meliputi:

- Kondisi udara dengan $\mathrm{T}_{\text {inlet }}=35^{\circ} \mathrm{C}$

- Refrigeran yang digunakan : R-134a

Tekanan kondensasi $=1492 \mathrm{kPa}$

Temperatur inlet kondensor $=104^{\circ} \mathrm{C}$

- Daya fan : 100 W.

2. Penentuan geometri kondensor Matriks geometri kondensor yang digunakan adalah sebagai berikut:

- Finned-tube panjang $=600 \mathrm{~mm}$

$O D=10,21 \mathrm{~mm}, I D=9,49 \mathrm{~mm}$, 
tube-pitch $=25,4 \mathrm{~mm}$

depth-row-pitch $=22 \mathrm{~mm}$.

- Jumlah row $=4$ dengan jumlah tube tiap row $=22$ (dari hasil trial \& error)

- Bahan tube : tembaga/copper dan bahan fin : aluminium-flat (tebal $=0,33$ $\mathrm{mm}$, pitch $=2.54 \mathrm{~mm}$ ).

Selain data batasan seperti telah ditunjukkan di point 1 dan 2, diperlukan lagi beberapa asumsi agar perhitungan termal dapat dilakukan. Asumsi-asumsi yang diambil mencakup:

- Tekanan udara inlet : $103 \mathrm{kPa}$.

- Kelembaban udara di inlet : $75 \%$ RH.

3. Penyusunan Konfigurasi Kondensor Berdasarkan data-data di atas, disusunlah konfigurasi dan koneksi tube. Gambar 3 menunjukkan matrik geometri dan parameter-parameter yang digunakan di dalam merancang kondensor.

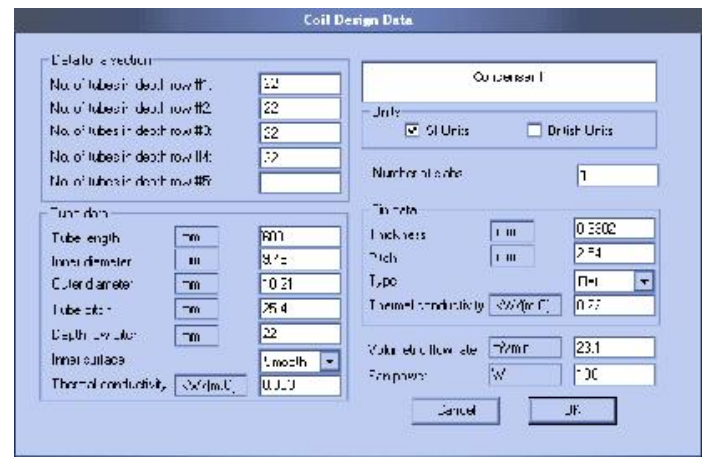

Gambar 3

Data masukkan untuk perancangan kondensor

4. Membandingkan hasil simulasi

Membandingkan dari setiap hasil simulasi desain kondensor untuk di dapatkan nilai optimal dari desain yang meliputi kapasitas pelepasan kalor, hasil simulasi distribusi temperatur dan fraksi uap refrigeran, hasil simulasi distribusi temperatur udara.

\section{HASIL DAN PEMBAHASAN}

\section{Hasil Perhitungan dan simulasi Evaporator}

Perhitungan termal dengan menggunakan konfigurasi sirkuit evaporator. Konfigurasi sirkuit tersebut terdiri dari susunan jumlah baris tube dan jumlah tube pada setiap barisnya, sebagaimana ditunjukkan pada Gambar 4.

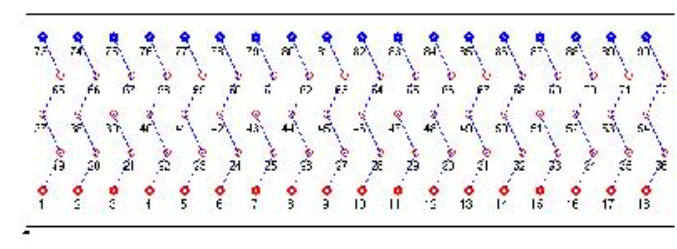

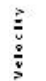

Gambar 4.

Konfigurasi dan sirkuit refrigerant perancangan evaporator.

Hasil simulasi menunjukkan kemampuan evaporator pada kondisi temperature saturasi refrigerant $5^{\circ} \mathrm{C}$, sedangkan temperature superheat keluar evaporator $6.35^{\circ} \mathrm{C}$. Temperatur udara masuk evaporator $26.5^{\circ} \mathrm{C}$ dengan kelembaban relatif $75 \%$. Tabel 1 menunjukan hasil simulasi distribusi fraksi uap dan temperature refrigerant. Dimana hasil simulasi pada temperatur udara keluar evaporator pada setiap sirkuit tube refrigerant adalah rata-rata $11.2^{\circ} \mathrm{C}$, dengan temperatur udara masuk evaporator sebesar $24^{\circ} \mathrm{C}$

Tabel 1.

Hasil Simulasi temperatur dan fraksi massa refrigerant

\begin{tabular}{|l|l|l|l|l|}
\hline Tube & Quality & $\begin{array}{l}\text { Temp } \\
\text { Ref }\end{array}$ & $\begin{array}{l}\text { Sub } \\
\text { cooling }\end{array}$ & $\begin{array}{l}\text { Ref. } \\
\text { Mass Fract }\end{array}$ \\
\hline \hline 73 & 1.00 & 11.2 & 6.2 & 0.056 \\
\hline 74 & 1.00 & 11.6 & 6.6 & 0.056 \\
\hline 75 & 1.00 & 11.3 & 6.3 & 0.056 \\
\hline 76 & 1.00 & 11.2 & 6.2 & 0.056 \\
\hline 77 & 1.00 & 11.2 & 6.2 & 0.056 \\
\hline 78 & 1.00 & 11.2 & 6.2 & 0.056 \\
\hline 79 & 1.00 & 11.2 & 6.2 & 0.056 \\
\hline 80 & 1.00 & 11.2 & 6.2 & 0.056 \\
\hline 81 & 1.00 & 11.2 & 6.2 & 0.056 \\
\hline 82 & 1.00 & 11.2 & 6.2 & 0.056 \\
\hline 83 & 1.00 & 11.2 & 6.2 & 0.056 \\
\hline 84 & 1.00 & 11.2 & 6.2 & 0.056 \\
\hline 85 & 1.00 & 11.2 & 6.2 & 0.056 \\
\hline 86 & 1.00 & 11.2 & 6.2 & 0.056 \\
\hline 87 & 1.00 & 11.2 & 6.2 & 0.056 \\
\hline 88 & 1.00 & 11.3 & 6.3 & 0.056 \\
\hline 89 & 1.00 & 11.2 & 6.2 & 0.056 \\
\hline 90 & 1.00 & 11.7 & 6.7 & 0.056 \\
\hline
\end{tabular}

Sedangkan hasil perhitungan termal menunjukkan kinerja sebagai berikut:

- Kapasitas total : 9,22 kW

- Temperatur udara keluar dari evaporator

$: 18,1^{\circ} \mathrm{C}$

- Flowrate refrigerant

- Temperatur refrigeran keluar evaporator superheat
: 226,8 kg/jam

$: 11,35^{\circ} \mathrm{C}$

: $6,35^{\circ} \mathrm{C}$ 
Sedangkan berat material evaporatorl

- Tubes \& return bends, copper $\quad: 4.7 \mathrm{~kg}$

- Fins, aluminum

- Total mass : $10.8 \mathrm{~kg}$

\section{Hasil perhitungan dan simulasi kondensor}

Gambar 5 menunjukkan beberapa konfigurasi sirkuit kondensor dengan mengacu pada jumlah tube sama yaitu 90 tube yang akan di simulasikan, dengan menggunakan data input perhitungan termal evaporator.

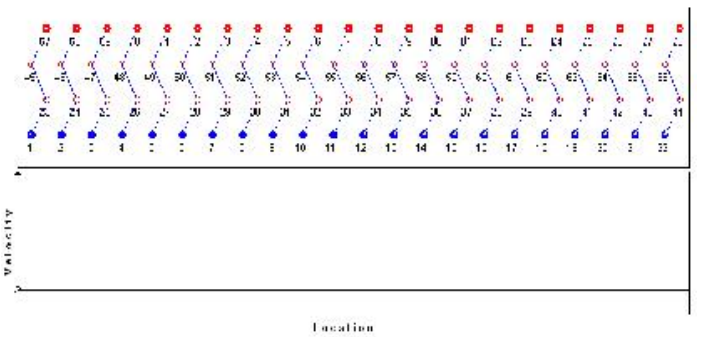

a. Konfigurasi sirkuit 1

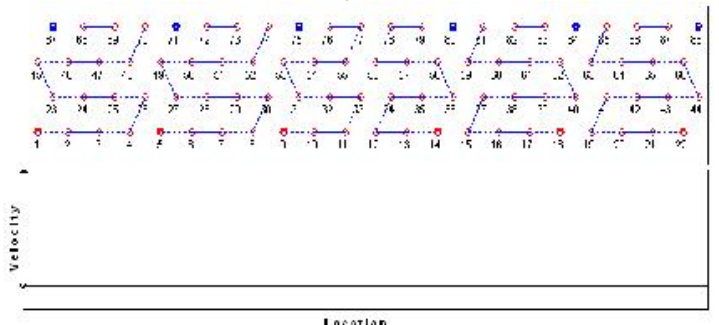

b. Konfigurasi sirkuit 2

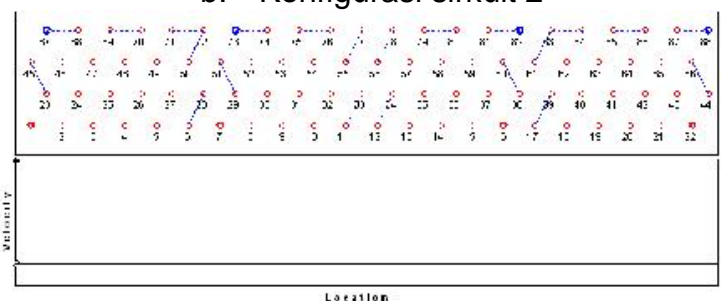

c. Konfigurasi sirkuit 3 Gambar 5.

Konfigurasi dan sirkuit tube refrigerant perancangan kondensor.

Hal yang menjadi perhatian pada perancangan kondensor untuk dapat memenuhi kebutuhan pendinginan pada kendaraan adalah temperature udara keluar dan kualitas fraksi refrigerant serta temperature keluar refrigerant. Tabel 2. Menunjukkan hasil simulasi kondensor pada 3 konfigurasi sirkuit. Berdasarkan fraksi uap, dimana hasil yang di dapatkan menunjukkan fraksi uap pada sirkuit 1 refrigeran keluar kondensor dalam kondisi uap basah dengan fraksi uap bernilai 0,4. Sedangkan untuk sirkuit 2 dan sirkuit 3 menunjukkan refrigerant keluar kondensor terkondensasi sempurna sehingga berbentuk refrigeran cair.

Sedangkan ditinjau dari distribusi temperatur refrigerant pada setiap sirkuit. Besarnya nilai temperature outlet kondensor pada konfigurasi sirkuit 1 sebesar $55^{\circ} \mathrm{C}$, untuk konfigurasi sirkuit 2 temperatur refrigeran keluar kondensor sebesar $41^{\circ} \mathrm{C}$ sedangkan untuk konfigurasi sirkuit 3 besarnya temperature refrigerant keluar kondensor $38^{\circ} \mathrm{C}$.

Besarnya nilai temperature udara outlet kondensor pada konfigurasi sirkuit 1 sebesar $37^{\circ} \mathrm{C}$, untuk konfigurasi sirkuit 2 temperatur udara keluar kondensor sebesar $38^{\circ} \mathrm{C}$ sedangkan untuk konfigurasi sirkuit 3 besarnya temperature udara keluar kondensor $38^{\circ} \mathrm{C}$.

Berdasarkan hasil simulasi ketiga konfigurasi di ketahui bahwa nilai kapasitas pelepasan kalor terbesar terdapat pada sirkuit 3 , dengan nilai kapasitas pelepasan kalor sebesar $26 \mathrm{~kW}$.

Tabel 2.

Data Hasil simulasi beberapa sirkuit

\begin{tabular}{|c|c|c|c|}
\hline Parameter & $\begin{array}{c}\text { Sirkuit } \\
1\end{array}$ & $\begin{array}{c}\text { Sirkuit } \\
2\end{array}$ & $\begin{array}{c}\text { Sirkuit } \\
3\end{array}$ \\
\hline \multicolumn{4}{|l|}{ Udara } \\
\hline Temp in $\left({ }^{\circ} \mathrm{C}\right)$ & 35 & 35 & 35 \\
\hline Temp out $\left({ }^{\circ} \mathrm{C}\right)$ & 37 & 38 & 38 \\
\hline Tekanan in (kPa) & 101.32 & 101.32 & 101.32 \\
\hline $\mathrm{RH}(\%)$ & 75 & 75 & 75 \\
\hline Flow rate $\left(\mathrm{m}^{3} / \mathrm{min}\right)$ & 407.23 & 407.23 & 407.23 \\
\hline \multicolumn{4}{|l|}{ refrigeran } \\
\hline Tekanan in (kPa) & 1492 & 1492 & 1492 \\
\hline Temp in $\left({ }^{\circ} \mathrm{C}\right)$ & 104 & 104 & 104 \\
\hline Temp out $\left({ }^{\circ} \mathrm{C}\right)$ & 55 & 41 & 38 \\
\hline Kualiats fraksi & 0.42 & 0 & 0 \\
\hline subcooling $\left({ }^{\circ} \mathrm{C}\right)$ & 0 & 7.47 & 6.16 \\
\hline Flow rate $(\mathrm{kg} / \mathrm{h})$ & 403,2 & 403,2 & 403,2 \\
\hline Total kapasitas (kW) & 16.30 & 24.82 & 26.01 \\
\hline
\end{tabular}

\section{SIMPULAN \& REKOMENDASI}

Berdasarkan hasil perhitungan, beban termal yang didapat telah memenuhi parameterparameter yang telah ditetapkan. Sedangkan matriks geometri alat penukar kalor untuk evaporator kabin depan dengan kapasitas 9 kW adalah sebagai berikut:

- Finned-tube dengan panjang $=500 \mathrm{~mm}$,

- $\mathrm{OD}=10,21 \mathrm{~mm}, \mathrm{ID}=9,49 \mathrm{~mm}$,

- tube-pitch $\quad=25,4 \mathrm{~mm}$

- depth-row-pitch $\quad=22 \mathrm{~mm}$.

- Jumlah row $=5$ 


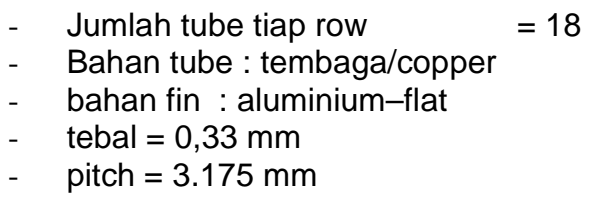

Untuk kondensor, hasil simulasi menunjukkan bahwa kapasitas pelepasan kalor yang paling optimal, terdapat pada sirkuit 3, dimana perhitungan beban termal yang didapat telah memenuhi parameter-parameter yang telah ditetapkan dengan nilai kapasitas pelepas kalor sebesar $26 \mathrm{~kW}$ Sedangkan matriks geometri alat penukar kalor untuk kondensor yang akan digunakan didalam system pengkondisian udara pada kabin kendaraan angkut personil adalah sebagai berikut:

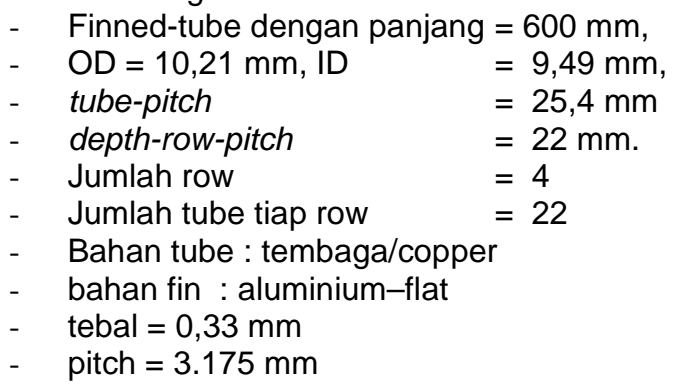

\section{UCAPAN TERIMAKASIH}

Saya ucapkan terimakasih kepada BT2MP BPPT yang telah memfasilitasi studi ini sehingga berjalan lancar. Ucapan terimakasih juga saya sampaikan kepada Bapak Achmad Maswan untuk kontribusinya dalam melakukan simulasi dan perhitungan untuk kajian ini.

\section{DAFTAR PUSTAKA}

1. ASHRAE Handbook, "HVAC Systems and Equipment", American Society of Heating , Refrigerating and Air Conditioning Engineers, Inc.,2012.
2. ASHRAE Handbook, "HVAC Fundamental", American Society of Heating, Refrigerating and Air Conditioning Engineers, Inc.,2009

3. ANSI/ASHRAE Standard 62.1-2007, Ventilation for Acceptable Indoor Air Quality. Atlanta: American Societyof Heating, Refrigerating and Air-Conditioning Engineers, Inc.

4. Domanski, P.A. EVAP-COND - Simulation models for finned-tube heat exchangers, Version 3, 2008, National Institute of Standards and Technology; Gaithersburg, MD, USA.

5. Domanski, P.A. David Yashar, Ken Kaufman Finned-Tube Heat Exchanger Simulation Program With Refrigerant Circuitry Optimization Capability, Miedzynarodowa Konferencja Chlodnicza, Poznan, 2008

6. W.K.Ding, J.F. Fan, Y.L.He, W.Q.Tao, Y.X.Zheng, Y.F.Gao, J.Song," A General Simulation Model For Performance Prediction Of Plate Fin-and-Tube Heat Exchanger With Complex Ciecuit Configuration', Applied Thermal Engineering 31 (2011) 3106-3116

7. Ihwan Haryono, Achmad Maswan, "Perhitungan Beban Termal Pada Sistem Pengkondisian Udara Kendaraan Militer Pengangkut Personel"

Mekanika Vol 11, UNS,2013

8. Cesare Maria Joppolo, Luca Molinaroli, Alberto Pasini," Numerical Analysis of The Influence of Circuit Arrangement on a finand-tube Condenser Performance", Case Studies in Thermal Engineering 6 (2015) 136-146

9. Piotr A. Domanski, David A. Yashar, Janusz Wojtusiak, "EVAP-COND Simulation models for finned-tube heat exchangers with circuitry optimization" , Version 4, 2016, National Institute of Standards and Technology, USA 